\title{
Noninvasive ventilation in cystic fibrosis patients with acute or chronic respiratory failure
}

\author{
B.P. Madden*, H. Kariyawasam", A.J. Siddiqi", A. Machin", J.A. Pryor", M.E. Hodson\#
}

\begin{abstract}
Noninvasive ventilation in cystic fibrosis patients with acute or chronic respiratory failure. B.P. Madden, H. Kariyawasam, A.J. Siddiqi, A. Machin, J.A. Pryor, M.E. Hodson. (C) ERS Journals Ltd 2002.

ABSTRACT: The experience of using noninvasive ventilation (NIV) in 113 adult cystic fibrosis (CF) patients with chronic respiratory failure, during episodes of acute deterioration in respiratory function is reported.

The patients aged 15-44 yrs were divided into three groups. Group A consisted of 65 patients (median forced expiratory volume in one second (FEV1)/forced vital capacity (FVC) $0.7 / 1.4 \mathrm{~L}$ ) who were on a lung transplant waiting list. Group B consisted of 25 patients (median FEV1/FVC 0.7/1.4 L) who were being evaluated for lung transplantation. Group C consisted of 23 patients (median FEV1/FVC 0.6/1.2 L) who were not being considered for lung transplantation.

The mean duration of NIV support for groups A, B and C was 61 (range: 1-600) days, 53 (1-279) days and $45(0.5-379)$ days respectively. Twenty-three patients in group $A$ subsequently received lung transplantation and 12 of these patients had a median survival of 39 months postsurgery. Thirty-nine patients died and three awaited transplantation. Five patients in group B received a transplant four of whom survived; thirteen patients died and seven awaited transplantation. Twenty patients in group $\mathrm{C}$ died.

Noninvasive ventilation improved hypoxia but failed to correct hypercapnia in these cystic fibrosis patients. Noninvasive ventilation is useful in the treatment of acute episodes of respiratory failure in cystic fibrosis patients with end-stage lung disease who have been accepted, or are being evaluated, for lung transplantation. For these patients, there is a possibility of prolonging life if they are successfully treated for their acute episode of respiratory failure until transplantation. In this group, treatment is not merely prolonging the process of dying.
\end{abstract}

Eur Respir J 2002; 19: 310-313.

*Dept of Cardiothoracic Medicine, St George's Hospital, and ${ }^{\#}$ Dept of Cystic Fibrosis, Royal Brompton Hospital, London, UK.

Correspondence: M.E. Hodson

Dept of Cystic Fibrosis

Royal Brompton Hospital

Sydney Street

London SW3 6NP

UK

Fax: 442073518052

\section{Keywords: Cystic fibrosis}

lung transplantation

noninvasive ventilation

Received: February 232001

Accepted after revision September 17 2001
Lung transplantation is an effective treatment option for selected cystic fibrosis (CF) patients with end-stage respiratory failure [1]. With careful attention to pre-operative assessment and postoperative medical care, survival of CF lung-transplant recipients is similar to patients who receive bilateral lung transplantation for non-CF medical conditions, and 1-yr actuarial survival is in the region of $75 \%[2,3]$. Nasal intermittent positive pressure ventilation (NIPPV), delivered noninvasively through a well-fitting nasal mask, has been shown to be of value in the management of patients with chronic respiratory failure $[4,5]$ and in acute respiratory failure [6]. Noninvasive mechanical ventilation (NIV) was used for $\mathrm{CF}$ patients as a bridge to transplantation [7]. The experience of using NIV in the management of 113 adult patients with end-stage $\mathrm{CF}$ lung disease is reported, and the authors have addressed how NIV should be applied to this patient group.

\section{Patients and methods}

The case records of 113 adult CF patients with end-stage lung disease who had been treated with
NIV between January 1989-December 1998 (10 yrs) were retrospectively reviewed. CF was diagnosed by sweat sodiums of $>70 \mathrm{mEq} \cdot \mathrm{L}^{-1}$ and/or genotype. The condition of each patient had deteriorated despite maximal medical treatment including physiotherapy, bronchodilators, appropriate antibiotics, controlled oxygen therapy and nutritional support. When the patient's clinical condition and arterial blood gases were such that either their degree of arterial hypoxia or hypercapnia with conventional treatment was considered to be a grave risk to their survival, they were ventilated mainly using the Brompton PneuPac ventilator (PneuPac, Luton, UK). The decision to instigate mechanical ventilatory support was a clinical decision based on clinical presentation, arterial blood gas analysis, rate of deterioration, pulse rate, respiratory rate and degree of exhaustion. Some patients were more tolerant of hypoxia and hypercapnia than others. NIV was established using the Brompton PneuPac ventilator (PneuPac) or a pressure-cycled ventilator. The Brompton PneuPac ventilator is a flow-generated, time-cycled machine which delivers a predetermined tidal volume either in response to the initiation of a spontaneous breath by the patient or automatically. Oxygen was added via a port in 
Table 1.-Selection criteria for transplantation in cystic fibrosis

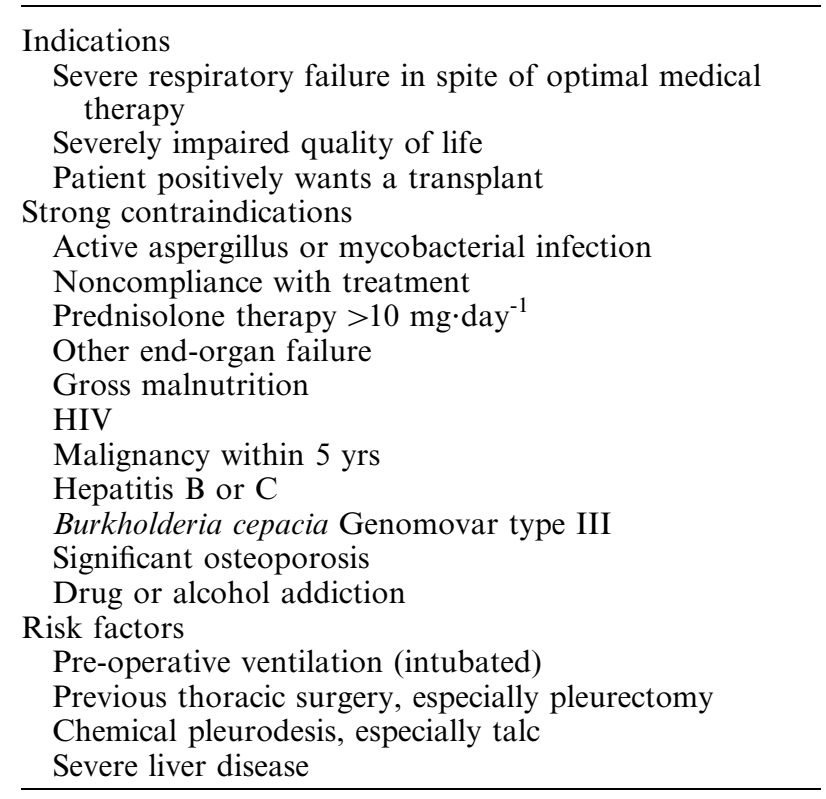

HIV: human immunodeficiency virus.

the nasal mask or through a T-piece connector at the ventilator end of the tubing. Tidal volumes used were considerably greater than during conventional mechanical ventilation to compensate for leaks through the mask and mouth. Patients needed detailed and careful instruction in the use of the machine, and most of them used a chinstrap when sleeping to avoid excess loss of gas through the mouth. The exact settings for flow rate, inspiratory time and expiratory time were adjusted depending on the patient's comfort and arterial blood gas values. The patients were monitored using a pulse oximeter together with routine nursing observations. Some less severely-ill patients were ventilated using a pressure-cycled machine, but if oxygenation was insufficient, they were transferred onto the volume/ time-cycled BromptonPac. The patients were divided into three groups, group A (patients on a lung transplantation waiting list), group B (patients being evaluated for lung transplantation), and group $\mathrm{C}$ (patients not being considered for transplantation). The indications for transplantation are shown in table 1.

\section{Results and outcome}

The age range for the 113 patients treated with NIPPV was 15-44 yrs. Group A consisted of 65 patients (30 males, 35 females). The median forced expiratory volume in one second (FEV1) and forced vital capacity (FVC) for patients in this group prior to commencing NIV was 0.7 and 1.4 L respectively, and arterial blood gas analysis on room air showed a median oxygen tension in arterial blood $\left(\mathrm{Pa}, \mathrm{O}_{2}\right)$ and carbon dioxide tension in arterial blood $\left(\mathrm{Pa}, \mathrm{CO}_{2}\right)$ of $6.6 \mathrm{kPa}$ (range: $3.9-11.0 \mathrm{kPa}$ ) and $10 \mathrm{kPa}(7.4$ $13.0 \mathrm{kPa})$, respectively. Patients in group $\mathrm{A}$ had a mean duration of NIV support of 61 days with a range of 1-600 days. During NIV (and entraining 2-4 L. min $^{-1}$ of $\mathrm{O}_{2}$ ) the median $P \mathrm{a}, \mathrm{O}_{2}$ and $P \mathrm{a}, \mathrm{CO}_{2}$ for the group was $8.8 \mathrm{kPa}(7.0-21.0 \mathrm{kPa})$ and $9.0 \mathrm{kPa}$ $(6.4-13.5 \mathrm{kPa})$, respectively (table 2$)$. Twenty-three patients in group A subsequently received lung transplantation, and 12 were alive at 1, 3, 8, 24, 25, 38, 39 $43,46,50,54$ and 62 months following lung transplantation. Thirty-nine patients in this group died while awaiting lung transplantation and three patients are awaiting transplantation.

Group B consisted of 25 patients (14 males, 11 females). The median FEV1/FVC for patients in this group, prior to commencing NIV, was 0.7 and $1.4 \mathrm{~L}$, respectively, and arterial blood gas analysis pre-NIV showed a median $P \mathrm{a}, \mathrm{O}_{2}$ of $6.4 \mathrm{kPa}(5.6-8.9 \mathrm{kPa})$ and $\mathrm{Pa}, \mathrm{CO}_{2}$ of $9.3 \mathrm{kPa}(6.3-11.3 \mathrm{kPa})$. During NIV (and entraining 2-4 L. $\mathrm{min}^{-1}$ of $\mathrm{O}_{2}$ ) $\mathrm{Pa}, \mathrm{O}_{2}$ and $P$ a, $\mathrm{CO}_{2}$ median values for patients in this group were $9.9 \mathrm{kPa}$ $(8.1-14.5 \mathrm{kPa})$ and $8.5 \mathrm{kPa}(5.5-11.1 \mathrm{kPa})$, respectively (table 2). Five patients in group $\mathrm{B}$ received lung transplantation and four were alive at 5, 9, 24 and 26 months following transplantation. One patient died at 7 months post-transplantation. Thirteen other patients in group B died and seven are awaiting transplantation.

Group C consisted of 23 patients (16 males, seven females). The median FEV1/FVC for patients in this group at the time of commencing NIV was $0.6 \mathrm{~L}$ and $1.2 \mathrm{~L}$, respectively, and arterial blood gas analysis on room air at that time provided a median $\mathrm{Pa}, \mathrm{O}_{2}$ of $7.6 \mathrm{kPa}(4.8-8.7 \mathrm{kPa})$ and $P \mathrm{a}, \mathrm{CO}_{2}$ of $8.5 \mathrm{kPa}$ $(6.1-13.6 \mathrm{kPa})$. While on NIPPV (and entraining 2-4 L.min ${ }^{-1}$ of $\mathrm{O}_{2}$ ) the median $\mathrm{Pa}, \mathrm{O}_{2}$ and $\mathrm{Pa}_{\mathrm{a}} \mathrm{CO}_{2}$ for patients in group $\mathrm{C}$ was $8.6 \mathrm{kPa}(6.3-22.8 \mathrm{kPa})$ and $9.6 \mathrm{kPa}(4.6-15.0 \mathrm{kPa})$, respectively (table 2). Twenty patients in group $\mathrm{C}$ died and three are alive.

Table 2. - Cystic fibrosis patients treated with noninvasive ventilation

\begin{tabular}{lcccccc}
\hline Patients & FEV1 L & FVC L & $\begin{array}{c}P a, \mathrm{O}_{2} \mathrm{kPa} \\
\text { Pre }\end{array}$ & $\begin{array}{c}P \mathrm{a}_{2} \mathrm{O}_{2} \mathrm{kPa} \\
\text { Post }\end{array}$ & $\begin{array}{c}P \mathrm{~Pa}, \mathrm{CO}_{2} \mathrm{kPa} \\
\text { Pre }\end{array}$ & $\begin{array}{c}P \mathrm{a}, \mathrm{CO}_{2} \mathrm{kPa} \\
\text { Post }\end{array}$ \\
\hline Group A (65) & $0.7(63)$ & $1.4(63)$ & $6.6(59)$ & $8.8(55)$ & $10.0(59)$ & $9.0(55)$ \\
Group B (25) & $0.7(17)$ & $1.4(17)$ & $6.4(20)$ & $9.9(20)$ & $9.3(20)$ & $8.5(20)$ \\
Group C (23) & $0.6(20)$ & $1.2(20)$ & $7.6(20)$ & $8.9(21)$ & $8.5(19)$ & $9.6(19)$ \\
\hline
\end{tabular}

Data are given as median values (numbers of patients on whom data was available). FEV1: forced expiratory volume in one second; FVC: forced vital capacity; $P \mathrm{a}_{2} \mathrm{O}_{2}$ : oxygen tension in arterial blood; $P \mathrm{a}_{2}, \mathrm{CO}_{2}$ : carbon dioxide tension in arterial blood. 
The mean duration of NIPPV support for groups A, B and C was 61 (1-600) days, 53 (1-279) days and 45 (0-379) days, respectively.

\section{Discussion}

The actuarial survival of the patients in group A who were transplanted was comparable to that of less sick nonventilated CF patients. The majority of centres do not conventionally endotracheally intubate and ventilate patients with end-stage $\mathrm{CF}$ either with acute or chronic deterioration, or those patients who are awaiting lung transplantation. This is because the use of a conventional ventilator is not without risk in those patients who are heavily infected with Pseudomonas aeruginosa and who have severe airflow obstruction [8]. Indeed, end-stage $\mathrm{CF}$ patients who are conventionally ventilated can develop pseudomonal toxaemia and systemic hypotension, which can lead to the development of multiple organ failure and render the patients unsuitable for transplantation. Barotrauma can lead to the development of pneumothorax and the patients may become colonized in an intensive care unit with multi-resistant bacterial organisms which can give rise to serious postoperative infection in the presence of immunosuppression. With the well-documented shortage of donor organs it is not possible to predict when patients will receive transplantation, and therefore, even if they do avoid the above complications while on mechanical ventilatory support in an intensive care unit, they may occupy a bed for many weeks, which could be used for patients who require other forms of intervention, (i.e. conventional cardiac and thoracic surgery which is usually associated with a shorter intensive care stay). It is also distressing for patients and their relatives to be managed in an intensive care unit, particularly if the patient develops progressive clinical deterioration, which ultimately renders him/her unsuitable for transplantation.

The use of NIV does not require intensive care unit facilities and is very cost-effective. Most of the patients on NIV were managed on a general CF ward or at home. At home, they received assistance from a trained relative or partner. The patients were able to communicate, eat, participate in chest physiotherapy and have their nutrition and general physical condition optimized more easily than when conventional mechanical ventilatory support was used. While on NIV, they were able to adjust the support provided by the machine by varying expiratory and inspiratory time and they felt to some degree in control of the situation. The interfaces were changed when necessary to alter pressure points on the face, and especially the bridge of the nose. A mask, nasal prongs or mouthpiece may have been used. Wellbeing was optimized during a very difficult time. Some of the patients used NIV only at night, as treatment for nocturnal hypoventilation. For selected patients, NIV gives a useful, but limited period of extra time during which suitable donor organs may be found.

Patients, while being assessed for lung transplantation, can be introduced to NIV and familiarized

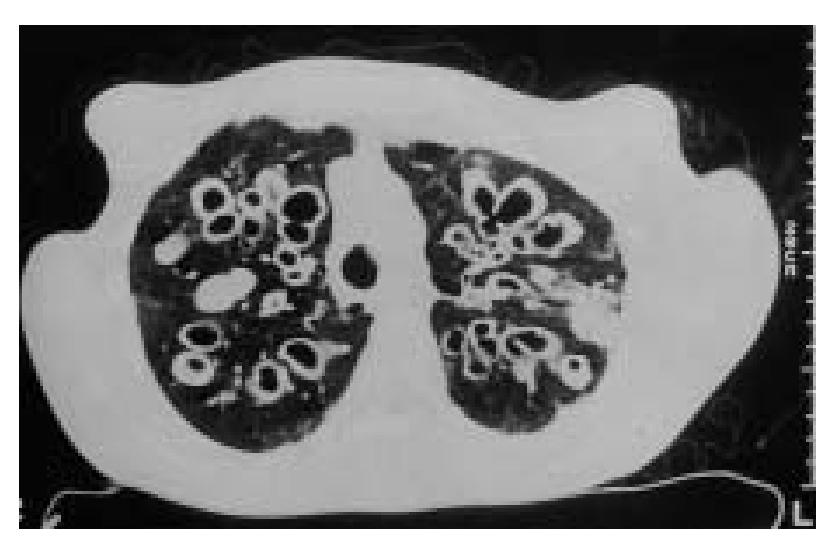

Fig. 1.-Computed tomography scan of the thorax of a patient with cystic fibrosis showing grossly-dilated bronchi.

with the regimen for use when clinically indicated. NIV is usually well tolerated when re-introduced. When considering NIV, even in the clinically stable patient, it is important to assess a very recent chest radiograph to identify any contraindications to ventilation (e.g. pneumothorax).

The patients described in this series were very ill with end-stage CF. Nasal ventilation was therefore used, rather than continuous positive airway pressure, which has been shown in kyphoscoliotic patients to be less effective, particularly in those patients with severe hypercapnia [9]. NIV improved arterial hypoxaemia, but failed to correct hypercapnia in the $\mathrm{CF}$ patients. This is in contrast to the results of patients treated with other lung diseases [4-6] and may be as a consequence of the increased dead space in the patients, resulting from their dilated bronchi (fig. 1). The nature of the patients' lung disease often necessitates NIV using a flow-generated, time-cycled machine delivering a predetermined tidal volume. Other devices, for example pressure-generated devices, may not provide adequate ventilatory support for $\mathrm{CF}$ patients with end-stage lung disease, as they do not provide a high enough pressure. It is appreciated, however, that some $\mathrm{CF}$ patients may be successfully ventilated using pressure-cycle ventilators.

The well-documented shortage of donor organs means that many patients with $\mathrm{CF}$ on lung transplant waiting lists will die before transplantation is possible. When patients are on NIV, they can stay in their own room, on the ward, where they know the nurses. They can continue to freely communicate with relatives and friends, and should the episode of deterioration turn out to be their final illness, their death is in many ways more dignified than if they died in the middle of a busy intensive care unit. NIV avoids endotracheal intubation and saves intensive care unit resources. It may also reduce the risk of infection and ischaemia of the airway after transplantation. If the patient is trained in the use of this device, they can use it postoperatively and reintubation in the early postoperative period may be avoided in some patients, or it may facilitate weaning from conventional mechanical ventilatory support postoperatively. NIV does, however, have the disadvantages of an unprotected airway and it provides no access for tracheal suction. 
The present study reports the largest series of cystic fibrosis patients receiving nasal ventilation and covers a number of years. It is a retrospective study with only limited data presently available. However, this study shows that noninvasive ventilation has a place in the management of patients with end-stage cystic fibrosis lung disease, who are already on a transplant waiting list or who are being evaluated for lung transplantation. Patients in group $\mathrm{C}$ were not being considered for transplantation either because they had one or more absolute contraindicating factors to lung transplantation [1], or they did not wish to proceed with lung transplantation. Care must be taken with patients for whom there is no way forward. These patients could spend many weeks on the ventilator before death and this would only lead to unnecessary prolongation of the inevitable. In this group of patients, symptoms of dyspnoea are more appropriately relieved by small doses of morphine. However, for those patients who are already assessed and accepted for transplantation and who suddenly deteriorate on account of unacceptable hypoxia and/or hypercapnia, the use of noninvasive ventilation may successfully treat the patient until transplantation.

Acknowledgements. The authors would like to thank M. Branthwaite who developed the Brompton PneuPac ventilator, A. Simonds who gave helpful advice, S. Hockley for typing the manuscript, and the many senior registrars, senior house officers, physiotherapists and nursing staff whose skills and hard work gave some of these young patients a chance to survive.

\section{References}

1. Madden BP. Lung transplantation in cystic fibrosis. In: Hodson ME, Geddes DM, eds. London, Chapman and Hall, Arnold, 2000; pp. 361-374.

2. Madden BP, Kamalvand K, Chan CM, Khaghani A, Hodson M, Yacoub M. The medical management of patients with cystic fibrosis following heart-lung transplantation. Eur Respir J 1993; 6: 965-970.

3. Yankaskas JR, Mallory GB. Lung transplantation in cystic fibrosis; consensus conference statement. Vol. VII, Section II. Cystic Fibrosis Foundation, 1996; pp. $1-19$.

4. Ellis ER, Bye PTD, Bruderer JW, Sullivan CE. Treatment of respiratory failure during sleep in patients with neuromuscular disease. Am Rev Respir Dis 1987; 135: 148-152.

5. Carroll M, Branthwaite MA. Control of nocturnal hypoventilation by nasal intermittent positive pressure ventilation. Thorax 1988; 43: 349-353.

6. Elliott MW, Steven MH, Philips GD, Branthwaite MA. Non-invasive mechanical ventilation for acute respiratory failure. BMJ 1990; 2: 358-360.

7. Hodson ME, Madden BP, Steven MH, Tsang VT, Yacoub M. Non-invasive mechanical ventilation for cystic fibrosis patients - a potential bridge to transplantation. Eur Respir J 1991; 4: 524-527.

8. Hodson ME. Management of respiratory failure in cystic fibrosis. Monaldi Arch Chest Dis 1998; 5: 537539.

9. Ellis EF, Grunstein RR, Chan S, Bye PT, Sullivan CE. Non-invasive ventilatory support during sleep improves respiratory failure in kyphoscolosis. Chest 1988; 94: 811-815. 